\title{
Secondary reinforcement based upon time out from avoidance
}

\section{ROBERT T. JONES, University of Exeter, Exeter, England 00260}

Rats were trained in a two-lever situation. Conventional free operant avoidance was programmed on one lever; on the other, time-out could be produced on a fixedinterval schedule. When the stimulus paired with time-out could be produced on a second-order schedule on the time-out lever, it maintained responding if time-out was conditional on its production, but not otherwise. The time-out stimulus was shown to have no intrinsic reinforcing properties.

Kelleher (1966) has shown that a pattern of responding can be maintained by a secondary reinforcer consisting of a briefly presented stimulus that is intermittently paired with positive reinforcement. $\mathrm{He}$ also describes these schedules, in which a pattern of behavior maintained by a schedule contingency is considered as a unitary response and is itself reinforced according to some schedule of reinforcement, as "secondorder schedules."

Verhave (1962) has shown that time out (TO) from avoidance can act as a reinforcer for the rat. He has also pointed out that the use of TO in this way always involves the manipulation of secondary reinforcement in that a neutral stimulus is paired with the TO. The effects of this (possible) secondary reinforcer are therefore confounded with those of the primary reinforcement of the avoidance schedule.

In this investigation an attempt was made to demonstrate positive secondary reinforcement due solely to a stimulus (STO) which was paired with TO from avoidance. The TO stimulus was produced on a second-order schedule while being intermittently paired with TO from avoidance. Both the TO schedule and the second-order schedule were fixed-interval (FI) schedules. If STO acts as a secondary reinforcer, it should maintain the pattern of FI responding in the same way that the TO does. Schedules with and without a limited hold were aiso used to test the conditions under which secondary reinforcement can be maintained.

\section{SUBJECTS}

Two male hooded rats, 7 months old at the start of the experiment, served as Ss. They were obtained from Animal Suppliers (London) Ltd.

\section{APPARATUS}

Two Lehigh Valley operant conditioning boxes, Nos. 1316 and 1417, were used. Each was enclosed in a sound-resistant cubicle, Lehigh Valley Models $1316 \mathrm{C}$ and $1417 \mathrm{C}$, respectively. There were two Lehigh Valley levers in one end-wall of each box. Illumination was provided either by a $7-W$ houselight or by pilot lights mounted above each lever.

The floor of each box consisted of 16 steel rods through which foot shock from a behavior apparatus constant power shock scrambler was delivered at a set $0.8 \mathrm{~mA}$. The duration of each shock was $0.38 \mathrm{sec}$, and this and other experimental contingencies were controlled by relays and circuitry in an adjacent room.

\section{PROCEDURE}

The rats were first trained to respond in a two-lever situation on a schedule of free operant avoidance (Sidman, 1953) with the response-shock and shock-shock intervals, both equal to $20 \mathrm{sec}$, programmed concurrently with a FI 10-min schedule on which TO could be produced

During avoidance periods, illumination was provided by the pilot lights above the levers. When the animal completed the FI requirement of the TO lever, these lights went out and the houselight came on. The duration of each TO was $10 \mathrm{~min}$, and after this time the reverse stimulus change occurred and the avoidance and TO schedules were automatically reinstated. No contingencies were programmed during $\mathrm{TO}$ and any responses which occurred were nonfunctional. The stimulus situation of houselight-on constitutes STO.

The experiment consisted of five stages. The avoidance schedule stayed the same throughout; only the TO schedule was altered. Stage 1 was the schedule described above. In Stage 2, a 10-sec occurrence of STO was programmed on a FI 5 -min schedule; alternated presentations of STO persisted and resulted in a TO period. This may be described as FR 2 (FI 5:STO) in Kelleher's (1966) terminology. Stage 3 was similar to Stage 2 except that the TO and STO schedules each had a 30-sec limited hold. In the final two stages, Stages 2 and 3 were repeated but with the avoidance contingency continuously present throughout the session, i.e., STO could still be produced for periods of $10 \mathrm{sec}$ or $10 \mathrm{~min}$ but was no longer associated with TO.

Performance was allowed to stabilize at each stage. The criterion of stability was that none of the TO response rates of the last three sessions should differ from the mean of these three sessions by more than $5 \%$. The results presented are the mean values.

A warm-up period of $90 \mathrm{~min}$ was allowed at the beginning of each session before any data were collected. Sessions were terminated when 11 TO periods had been produced and were run on consecutive days. RESULTS

The quarter-lives of the TO responding in Stage 1 show that both animals showed accelerating response rates during each FI, i.e., scalloped records were produced. This was particularly noticeable for No. 512 .

Time-out responses during the first $5 \mathrm{~min}$, first FI component, of each avoidance period increased markedly when STO was introduced on an FI 5-min schedule in Stage 2, and the quarter-lives again indicated scalloped response records. However, when a limited hold was introduced in Stage 3, performance essentially returned to that of Stage 1 with little responding in the first $5 \mathrm{~min}$ of each avoidance period, although the quarter-life of No. 519 increased from $32 \%$ to $65 \%$. The limited hold was introduced when the Ss were actually producing STO on a FI schedule and they continued to produce it occasionally for five to six sessions even with the limited hold. But this became progressively rarer, and by the time performance stabilized responding to produce STO had extinguished.

Table 1

Responses on the TO Lever at each Stage of the Experiment

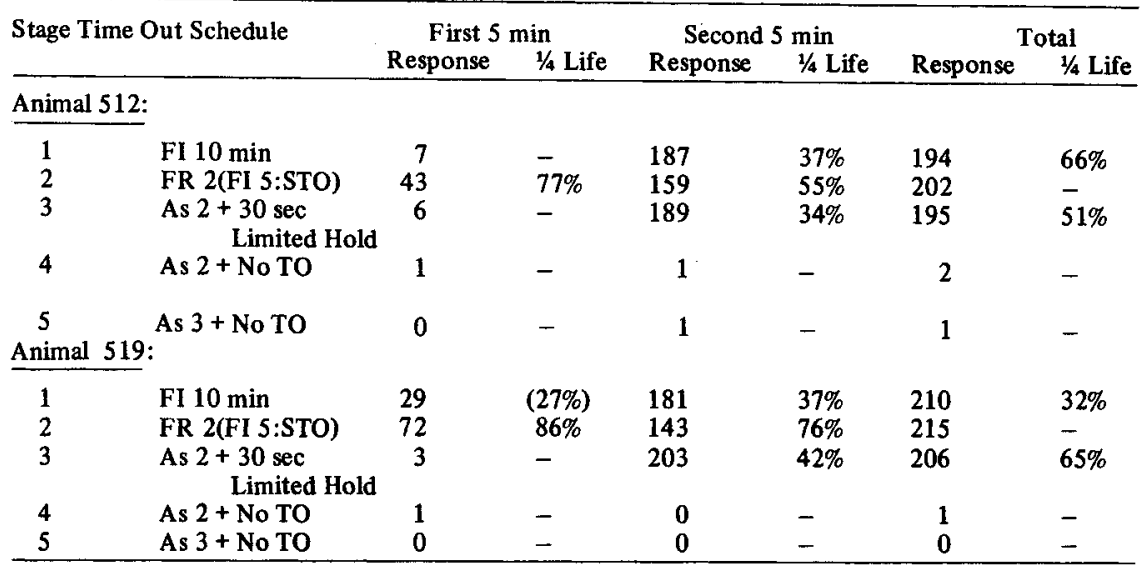


The results for Stages 4 and 5 demonstrate that a period STO alone could not support responding on the TO lever.

Although responding in the first $5 \mathrm{~min}$ of each avoidance period increased in Stage 2, there was no overall increase in the TO rate, and TO rates in the first halves of the avoidance periods were never as high as those in the second halves.

\section{DISCUSSION}

The typically scalloped FI performance obtained on the TO lever is similar to that obtained under appetitive reward. Neither Verhave (1962) nor Findley \& Ames (1965) found this in their investigations of FI schedules of production of TO from avoidance, but the patterns of FI responding that they found also differed from one another. The reasons for these discrepancies are not clear at present.

In Stage 2, typical FI responding was also maintained by STO when it was programmed on a second-order schedule. However, when STO was not associated with TO, in Stages 5 and 6, it could not maintain responding. This confirms that STO is a secondary reinforcer and that the absence of the avoidance contingency is the primary reinforcer.

The secondary reinforcement demonstrated in Stage 2 was quite weak and was not reflected in a higher overall $\mathrm{TO}$ response rate. This was probably because of the very good temporal discrimination shown, and is illustrated by the high quarter-lives. Nevertheless, this experiment demonstrates a technique whereby positive secondary reinforcement can be established in a situation using only negative primary reinforcement (electric shock).

Much attention has been focused on the conditions for the establishment of a stimulus as a secondary reinforcer. These are operationally similar to those involved in the classical conditioning paradigm (Kimble, 1961): There must be a conditional relationship between the stimulus and primary reward (secondary reinforcement) or unconditioned stimulus (classical conditioning). Temporal contiguity is only one of several relationships, or conditioning techniques, which are available (Pavlov, 1927). Similar ideas are embodied in the current hypotheses that a secondary reinforcer must be a discriminative stimulus (Keller \& Schoenfeld, 1950) or possess informational value (Miller, 1961).

The present results are compatible with the above formulations but it is the maintenance of secondary reinforcement which is emphasized. Secondary reinforcement was not established and then "tested" in a situation where it had no relevance to primary reward, e.g., Egger \& Miller (1963). That STO did not support responding when it was available on FI $5 \mathrm{~min}$ with a limited hold, although it did without the limited hold, suggests that the maintenance of secondary reinforcement requires that the production of primary reinforcement be conditional upon the production of the secondary reinforcer. The introduction of the limited hold means that STO can be "missed" and yet TO still remains available contingent on the first $\mathrm{TO}$ response $10 \mathrm{~min}$ after the start of the avoidance period. If STO is missed, the schedule becomes that of Stage 1; but if it maintains responding, then the schedule becomes equivalent to that of Stage 2. When there is no limited hold, the first TO response after $5 \mathrm{~min}$ must produce STO and a further $5 \mathrm{~min}$ must elapse before a TO period can possibly be produced, i.e., STO must be produced here.

If emphasis is placed on the conditional nature of secondary reinforcement and upon the maintenance of secondarily reinforced responding, and not upon the fact that approximate contiguity between a stimulus and primary reinforcement is an optimal method for establishing the stimulus as a secondary reinforcer (Bersh, 1951), it may be possible to explain the durability of secondary reinforcement outside the laboratory, which often seems paradoxical when compared with its apparent ephemeral nature under laboratory conditions (Razran, 1955). In everyday life, primary reward may be obtainable only if a secondary reinforcer is first procured; this conditional relationship may be maintained even though the primary and secondary reinforcers are not paired contiguously.

\section{REFERENCES}

BERSH, P. J. The influence of two variables upon the establishment of a secondary reinforcer for operant responses. Journal of Experimental Psychology, 1951, 41, 62-73.

EGGER, M.D., \& MILLER, N.E. When is a reward reinforcing? An experimental study of the information hypothesis. Journal of Comparative \& Physiological Psychology, 1963, 56, 132-137.

FINDLEY, J. D., \& AMES, L. L. A note on time out from avoidance with the chimpanzee. Journal of the Experimental Analysis of Behavior, 1965, 8, 419-423.

KELLEHER, R. T. Conditioned reinforcement in second-order schedules. Journal of the Experimental Analysis of Behavior, 1966, 9, 475-485.

KELLER, F. S., \& SCHOENFELD, W. N. Principles of psychology. New York: AppletonCentury-Crofts, 1950.

KIMBLE, G. A. Hilgard and Marquis' conditioning and learning. New York: Appleton-CenturyCrofts, 1961 .

MILLER, N. E. Analytic studies of drive and reward. American Psychologist, 1961, 16, 739-754.

PAVLOV, I. P. Conditioned reflexes. Translated by G. V. Anrep. London: Oxford University Press, 1927.

RAZRAN, G. A note on second-order conditioning and secondary reinforcement. Psychological Review, 1955, 62, 327-332.

SIDMAN, M. Two temporal parameters of the maintenance of avoidance behavior by the white rat. Journal of Comparative \& Physiological Psychology, 1953, 46, 253-261.

VERHAVE, T. The functional properties of a time out from an avoidance schedule. Journal of the Experimental Analysis of Behavior, 1962, 5, 391-422.

NOTE

1. This research was supported by a research studentship from the Science Research Council, U.K.

\section{Task and species generality of the "helplessness" phenomenon}

WILLIAM BRAUD, BARRY WEPMAN, and DANE RUSSO, University of Houston, Houston, Tex. 77004

Three groups ( $N=9$ ) of male albino mice were given six daily 2-h exposures to escapable, inescapable, or no electric shock. Shock was programmed on a 30-sec-on/30-sec-off alternating schedule. The pole-climbing behavior of an escapable shock $S$ could terminate or prevent shock both for itself and for its yoked inescapable shock pair-member. All Ss then were given, after a 24-h rest, five water-escape trials in which swimming time was measured. The escapable shock Ss learned the water-escape task faster than the no shock control Ss. The inescapable shock Ss swam increasingly slower over trials.
Seligman and his associates (Overmier \& Seligman, 1966; Seligman \& Maier, 1967) have reported that exposure of dogs to inescapable shocks under a variety of conditions reliably resulted in interference with subsequent escape-avoidance behavior in a new situation. Such proactive interference did not occur when, in the first task, shock termination was made response contingent. Seligman has rejected shock adaptation and competing skeletal response interpretations in favor of a "learned helplessness" hypothesis. According to this hypothesis, when shock termination is independent of responding, the S learns that the probability of shock termination in the presence of any given response does not differ from the probability of shock termination in the absence of that response; 